\title{
Exploring the Coastal Tourism Potentials of Lagos
}

\author{
Nnezi Uduma-Olugu ${ }^{1} \&$ Henry N. Onukwube ${ }^{2}$ \\ ${ }^{1}$ Department of Architecture, University of Lagos, Akoka, Yaba, Lagos, Nigeria \\ ${ }^{2}$ Department of Building, University of Lagos, Akoka, Yaba, Lagos, Nigeria \\ Correspondence: Nnezi Uduma-Olugu, Department of Architecture, University of Lagos, Akoka, Yaba, Lagos, \\ Nigeria. Tel: 234-802-320-0773. E-mail: nnezi.udumaolugu@gmail.com
}

Received: February 2, 2012 Accepted: June 1, 2012 Online Published: June 28, 2012

doi:10.5539/jsd.v5n7p156 URL: http://dx.doi.org/10.5539/jsd.v5n7p156

\begin{abstract}
Nigeria, just like the ASEAN countries, is in the process of metamorphosizing into a developed country. In its quest for developing other sectors of the economy to diversify from its main stay which is oil, Nigeria is looking to tourism as a possible alternative income earner for the nation. Growing statistics indicate the increasingly financial gains in exploiting the untapped wealth of coastal tourism: it is increasingly an area of interest whose potential lies hugely unexploited in Nigeria. Lagos, its former capital, is one of Nigeria's coastal cities. Water-based sites in the city are largely neglected or grossly under-utilized thereby wasting their natural recreational potentials. This research seeks to examine the existing water tourism destinations, identify the problems causing lack of popularity, and subsequently proffer solutions enabling policy makers in government and private sector plan better. Data were collected through the administration of structured questionnaires and interviews from sixty randomly selected users and industry practitioners in Tarzan Jetty, Ozumba Mbadiwe Waterfront, Bar Beach Harbour and the Marina Waterfront. Data collected were analyzed using descriptive statistics and mean item score. Result of the survey showed that all the four water-based tourist destinations experience lack of infrastructure, most especially functional ferries or other water transport, piers, canoes and boats for pleasure rides and sightseeing, properly designed areas for relaxation and passive leisure, lack of security and non availability of restaurants, shopping facilities and conveniences. The provision of these infrastructures will definitely improve the current state of coastal tourism in Lagos.
\end{abstract}

Keywords: coastal tourism, facilities, patronage, potentials, Lagos

\section{Introduction}

Tourism is an interdisciplinary field that uses input from several industries. It is often viewed as an expression of human behavior. Tourism is conceptualized as the set of ideas, theories or ideologies for being a tourist. Coastal tourism refers to tourism plans prepared to promote coastal activities, namely sea-sand-sun (3S) type of activities. Till the end of 1980's coastal tourism development was facing its best times, but after that period especially with the beginning of 90s such coastal tourism movements began to show distinct signs of weaknesses (Lickorish \& Jenkins, 1997). The weakness that coastal tourism market faced, had certain reasons one of which was the stuck of coastal market destinations into high-rise buildings with lack of infrastructure, polluted air-water, destroyed natural resources, overuse of carrying capacity etc. Unplanned developments caused unrecoverable damages on coasts of popular tourist destinations due to the uncoordinated and unplanned tourist developments. On the other hand it has been recognized that tourism Industry should preserve and protect the environment and natural attractions to ensure the continuity of tourist travels (McIntosh et al., 1995). Popular coastal tourism destinations were facing not only environmental problems but also quality problems in accommodation facilities, provision of water sports, shopping and auxiliary facilities, maintenance of existing facilities, provision of catering services etc. due to the high population movements, congestion and overcrowding in peak seasonal period (Lickorish \& Jenkins, 1997). Burton (1995) is of the opinion that the 'coastal tourist' seeks first and foremost a clean, sandy beach on the coast, comfortable for sunbathing and safe for swimming.

Another problem of coastal tourism, is the changing tastes of the consumers. Regarding these changing tastes, consumers started to be in search for more varied products than traditional sun-sea-sand type of summer activities i.e. excursions to authentic and mystical places, traditional lifestyles of local communities, healthy and 
preserved natural environments etc. Another issue within this concept was a move away from single long vacation to fragmented- shorter holidays due to greater work pressures (Küce, 2001).

A few studies in Nigeria have addressed the possibility of exploring the coastal tourism potentials of Lagos. Adejumo (2010) reviewed the rural contribution to coastal tourism in his study on the Eleko beach tourism. The outcome of his work is limited to only one particular community. Hence this study intends to examine tourism activities in four coastal destinations to provide a more robust and comprehensive result. In order to achieve this aim, the study is set up to achieve the under-listed objectives;

1) To identify patronage of coastal tourism destinations in Lagos.

2) To determine the relative importance index of facilities provided at existing coastal destinations in Lagos.

3) To evaluate the importance attached to identified coastal tourism factors at existing coastal destinations in Lagos.

The study postulates that the facilities provided and the identified coastal tourism factors do not have any significant impact on coastal tourist destinations in Lagos.

\section{Literature Review and Conceptual Issues}

\subsection{Facilities and Infrastructure at Various Coastal Tourism}

Aziz and Zainol (2009) listed facilities at tourism destinations, in their study on the Destinations in Peninsular Malaysia as: highway and roads, easy to access, hygienic restaurants, public transportation, safe place, health service, inexpensive service, suitable accommodation, clean natural environment, various accommodation, low travel cost, signage, friendly local people, protected nature reserve, agriculture-based products, local arts and crafts, local cultural activity, tourist information, variety of local cuisine, parking area and space, relaxing, exciting, pollution-free, not overcrowded, place of good reputation, recreational activities, adventurous activities, shopping centers, sports and gaming facilities, many tourist attractions, beautiful scenery, fascinating atmosphere, variety of flora and fauna, beautiful buildings, cool climate, beautiful mountains, family-oriented and good nature trails. In their study, Oldham, Creemers and Rebeck (2000) observed that the supply of tourism facilities requires a capital input like land and infrastructure, and also other supporting inputs such as transport, water, power, food and beverages and sundry services. Rutin (2010) identified one of the factors for selecting a tourism destination as the absence of recent political or security unrest in the host countries or in close neighbouring countries.

Planning is essential to stimulate tourism development and its sustainability. Without tourism planning, many unintended consequences may develop, causing tourist and resident dissatisfaction. These include damage to the natural environment, adverse impacts upon the cultural environment, and a decrease in potential economic benefits. The negative experience of many unplanned tourist destinations and the success of local and regional planned destinations demonstrate that tourism development should be based on a planning process that includes a solid assessment of the resources at the destination and their attractiveness potential (Blank, 1989; Formica, 2000; Gunn, 1994; Inskeep, 1994).

\subsection{Seasonality and Patronage of Tourist Destinations}

Rutin's (2010) comparative study of coastal tourism destinations between Croatia and Tunisia found that many coastal resorts in Croatia have low patronage (practically empty) in winter, thereby affecting usage of such facilities and the morale of workers who depend on the tourism industry for their employment and sustenance. This was not the case in Tunisia where the seasonal effect was lower, the employees were skilled and a large portion of the jobs in tourism were permanent and stable throughout the year. This stability was revealed by the ability of the tourism industry in Tunisia to successfully handle an unusually high peak of tourism during the winter period.

The impact of seasonality on coastal tourism was also highlighted by Rutin (2010). He found that the seasonality effect on the incoming tourism of Croatia showed a 100 percent cumulative figure of the monthly amount of incoming tourists in Croatia and Tunisia. More than 50 percent of the incoming tourism in Croatia entered during only two months, July and August, while in winter it was almost impossible to find a month of high tourism in Croatia. In Tunisia during August the incoming tourism was at its highest peak, but during most of the other months the incoming tourism was more or less the same. This shows that the season of a tourist's visit can affect patronage of a coastal tourism destination. 


\subsection{Improvement of Facilities at Coastal Tourism Destinations}

The introduction of entertainment and sports within coastal destinations may also improve coastal tourism. Entertainment refers to the facilities, which offer visitors a wide range of attractions and activities i.e. technology, fun, sports, science etc. in a relatively compact area. Theme parks are among the important entertainment activities.

Sports is a broad category depending on how sport activities are classified. Sports Tourism contains wide variety of sports activities from team sports like basketball, football to adventure sports like white water diving, rafting etc and even to yachting. Although many of the Classifications overlap with each other, general sub-categories may be defined as: adventure sports, recreation and out-door sport activities. Trekking and cycling may be considered among the recreational outdoor activities. Additionally golf, which is a very popular environment oriented sport, may be considered within recreational activities.

\section{The Research Survey}

A questionnaire survey was undertaken to determine the opinion of respondents on tourism potentials of Lagos. A three page questionnaire, accompanied by a covering letter was administered on respondents within four coastal tourism destinations. The letter indicated the objective of the research. The questionnaire design was based on a combination of an extensive review of literature dealing with tourism and the authors' general knowledge of tourism in Nigeria. The questionnaire contained, among others, the problems causing lack of popularity of coastal tourism in Lagos.

The questionnaire was distributed to 120 randomly selected respondents in four tourist destinations. Overall, all the 120 respondents returned completed questionnaires in a usable format, representing a $100 \%$ response rate.

\section{Data Analysis and Results}

The statistical analyses of the data obtained were carried out with the aid of Statistical Package for Social Sciences (SPSS). Twenty-eight factors that could cause lack of popularity of coastal tourism were identified from literature and used for the study. The respondents were required to rate the impact of each factor on a 5-point Likert scale using 1 for little impact, 2 for little impact, 3 for critical impact, 4 for very critical impact and 5 for extremely critical impact. Critical impact index for each factor was computed using mean item score. These scores were then ranked in descending order. The reliability of the survey instrument was tested using Cronbach alpha reliability test. The Cronbach reliability coefficient alpha is 0.867 with F-statistic of 59.405, $\mathrm{p}=0.0001$ indicating that the measuring instrument is reliable at $5 \%$ significance level.

\subsection{Soci-Demographic Characteristics}

\subsubsection{Age Distribution of Respondents}

Table 1 depicts the age distribution of respondents. Majority of the respondents $41.7 \%$ are within the age range of (21-30) years. This closely followed by those in age range of (31-40) years. This result indicates that most of the tourist in the selected tourist destinations are young (see Table 1 for more details).

\subsubsection{Gender of Respondents}

Table1 shows the result of a question that sought to know the gender of the respondents. Most of the respondents were predominantly male (58.5\%). Female respondents were smaller in population $(41.5 \%)$.

\subsubsection{Educational Qualification}

Table 1 indicates that majority of the respondents are first degree holders, $48.7 \%$. Others are respondents that attended polytechnic, $21 \%$, secondary school, $16 \%$, M.Sc or Ph.D, $11.8 \%$, primary school, $1.7 \%$ while those that had no academic qualification recorded $0.8 \%$. The result shows that most of the respondents are well educated and are competent to answer the questions in the research instrument. 
Table 1. Demographic characteristics of respondents

\begin{tabular}{|c|c|c|c|c|c|}
\hline & VARIABLES & Freq & Cum. Freq. & $\%$ & Cum. \% \\
\hline \multirow[t]{5}{*}{1} & Age $(\mathrm{N}=120)$ & & & & \\
\hline & $11-20$ years & 23 & 23 & 19.2 & 19.2 \\
\hline & $21-30$ years & 50 & 73 & 41.7 & 60.9 \\
\hline & $31-40$ years & 37 & 110 & 30.8 & 91.7 \\
\hline & $41-60$ years & 10 & 120 & 8.3 & 100 \\
\hline \multirow[t]{3}{*}{2} & Gender $(\mathrm{N}=118)$ & & & & \\
\hline & Male & 69 & 69 & 58.5 & 58.5 \\
\hline & Female & 49 & 118 & 41.5 & 100 \\
\hline \multirow[t]{7}{*}{3} & Highest educational qualification $(\mathrm{N}=119)$ & & & & \\
\hline & None & 1 & 1 & 0.8 & 0.8 \\
\hline & Primary School & 2 & 3 & 1.7 & 2.5 \\
\hline & Secondary School & 19 & 22 & 16 & 18.5 \\
\hline & Technical School or polytechnic & 25 & 47 & 21 & 39.5 \\
\hline & Bsc & 58 & 105 & 48.7 & 88.2 \\
\hline & M.Sc. or Ph.D. & 14 & 119 & 11.8 & 100 \\
\hline \multirow[t]{6}{*}{4} & Ethnicity $(\mathrm{N}=120)$ & & & & \\
\hline & Igbo & 31 & 31 & 25.8 & 25.8 \\
\hline & Yoruba & 54 & 85 & 45 & 70.8 \\
\hline & Hausa/Fulani & 9 & 94 & 7.5 & 78.3 \\
\hline & Other tribes & 25 & 119 & 20.9 & 99.2 \\
\hline & Foreigners & 1 & 120 & 0.8 & 100 \\
\hline
\end{tabular}

Freq=Frequency, cum $=$ cumulative, $\%=$ percentage

\section{2}

\subsubsection{Water Based Facilities}

Table two shows the level of usage of water based facilities. Majority of the respondents (43.7\%) stated that they use water based facilities occasionally any time they visit coastal tourist destinations (See Table 2 for other details).

\subsubsection{Spending Per Trip}

Table 2 indicates the spending pattern of respondents during their visit to various tourist destinations. Most of the respondents spend less than N500 (32.2\%).This followed by those that spend less than N2,000 - N5,000 (27.8\%). The respondents that spend N500 - N1000 came third with a total percentage of (27\%). The implication of this result is that most tourists spend minimal amount of money during their visit, which means that that tourism is not generating adequate revenue in Lagos. Moreover, the result also indicates that most tourists do not seek lodging facilities within the tourist destinations.

\subsubsection{What Activities Do You Take Part in?}

A question was asked the respondents to indicate the activities that they are involved in during their visit. The result is indicated in Table 2. Majority of the respondents (34.2\%) indicated that they walk during the visit. Horse riding came second (17.5\%). Others are Swimming (16.6\%), dancing (14.2\%) and boating (10\%).

\subsubsection{Population of Tourists}

Table 2 indicates that majority of the respondents (28\%) agreed that the population of the tourists is usually up to 20 people each time they visit (See Table 2 for other details).

\subsubsection{Do You Go in the Company of Others?}

Table 2 shows that most of the respondents go to tourist destinations in groups $(31.1 \%)$, others go as couples $(30.3 \%)$, by self $(21 \%)$, as a family $(16.8 \%)$.

\subsubsection{What Season of the Year Do You Visit?}

Respondents were asked to indicate the period of the year they usually go to tourist destinations. Most of the respondents (43.1\%) indicated all year round. Others are October to December (37.9\%), April to June (8.6\%), 
July to September $(8.6 \%)$ and January to March $(1.7 \%)$. The result confirms the attitude of most Lagosians who usually visit destinations during festivities and holidays.

\subsubsection{What Time of the Day Do You Visit?}

Respondents were asked to indicate the time of the day they normally visit tourist destinations. Table 2 indicates the results. Most of the respondents confirmed that they visit in the afternoon (43.6\%). Others are evenings $(27.4 \%)$, any time $(20.5 \%)$, and morning hours $(8.5 \%)$.

Table 2. Patronage of coastal tourism destinations

\begin{tabular}{|c|c|c|c|c|c|}
\hline & Options & Freq & Cum. Freq. & $\%$ & Cum. \% \\
\hline \multirow[t]{6}{*}{1} & Water Based Facilities ( $\mathrm{N}==119$ ) & & & & \\
\hline & I rarely use water based facilities & 28 & 28 & 23.5 & 23.5 \\
\hline & I use it seasonally & 15 & 43 & 12.6 & 36.1 \\
\hline & I use it occasionally & 52 & 95 & 43.7 & 79.8 \\
\hline & I use it often & 11 & 106 & 9.2 & 89.1 \\
\hline & I use it regularly & 13 & 119 & 10.9 & 100 \\
\hline \multirow[t]{6}{*}{2} & Spending per trip $(\mathrm{N}=115)$ & & & & \\
\hline & Less than N500 & 37 & 37 & 32.2 & 32.2 \\
\hline & N500-N1000 & 31 & 68 & 27 & 59.1 \\
\hline & N2000-N5000 & 32 & 100 & 27.8 & 87 \\
\hline & $\mathrm{N} 10,000-\mathrm{N} 20,000$ & 12 & 112 & 10.4 & 97.4 \\
\hline & Above N20,000 & 3 & 115 & 2.6 & 100 \\
\hline \multirow[t]{7}{*}{3} & What activities do you take part in? $(\mathrm{N}=120)$ & & & & \\
\hline & Swimming & 20 & 20 & 16.6 & 16.6 \\
\hline & Horse riding & 21 & 41 & 17.5 & 34.1 \\
\hline & Walking & 41 & 82 & 34.2 & 68.3 \\
\hline & Dancing & 17 & 99 & 14.2 & 82.5 \\
\hline & Boating & 12 & 111 & 10 & 92.5 \\
\hline & Others & 9 & 120 & 7.5 & 100 \\
\hline \multirow[t]{6}{*}{4} & When you visit, are there usually $(\mathrm{N}=118)$ & & & & \\
\hline & Up to 10 people & 20 & 20 & 16.9 & 16.9 \\
\hline & Up to 20 people & 33 & 53 & 28 & 44.9 \\
\hline & Up to 50 people & 32 & 85 & 27.1 & 72 \\
\hline & Up to 100 people & 22 & 107 & 18.6 & 90.7 \\
\hline & More than 100people & 11 & 118 & 9.3 & 100 \\
\hline \multirow[t]{6}{*}{5} & Do you usually go, $(\mathrm{N}=119)$ & & & & \\
\hline & By yourself & 25 & 25 & 21 & 21 \\
\hline & As a couple & 36 & 61 & 30.3 & 51.3 \\
\hline & As a family & 20 & 81 & 16.8 & 68.1 \\
\hline & In a group & 37 & 118 & 31.1 & 99.2 \\
\hline & In more than one group & 1 & 119 & 0.8 & 100 \\
\hline \multirow[t]{6}{*}{6} & At what time of the year do you normally visit? $(\mathrm{N}=16)$ & & & & \\
\hline & January to March & 2 & 2 & 1.7 & 1.7 \\
\hline & April to June & 10 & 12 & 8.6 & 10.3 \\
\hline & July to September & 10 & 22 & 8.6 & 19 \\
\hline & October to December & 44 & 66 & 37.9 & 56.9 \\
\hline & All year round & 50 & 116 & 43.1 & 100 \\
\hline \multirow[t]{5}{*}{7} & At what time of the day do you normally visit? $(\mathrm{N}=117)$ & & & & \\
\hline & Morning hours & 1 & 10 & 8.5 & 8.5 \\
\hline & Afternoon & 51 & 61 & 43.6 & 52.1 \\
\hline & Evenings & 32 & 93 & 27.4 & 79.5 \\
\hline & Any time & 24 & 117 & 20.5 & 100 \\
\hline
\end{tabular}

Freq $=$ Frequency, cum $=$ cumulative, $\%=$ percentage 


\subsection{Importance Attached to Facilities at Existing Coastal Destinations}

Importance indices for the 15 variables are shown Table 2. From the table the four most important facilities available at the surveyed sites (based on the ranking of the mean item scores (MIS)) are: Conference facilities (0.91); Lodging (0.89); Water Sports (0.87); and Swimming (0.85). The four least important facilities are: Beachfront (0.68); Restaurant and Bar (0.60); and Conveniences/ Parking (0.58).

The importance of 15 existing facilities on the four coastal tourist destinations was assessed from the responses. The five most occurring facilities, based on ranking of the mean item score are: Conference facilities (0.91), lodging (0.89), water sports (0.87), swimming (0.85), ferries, piers, marina (0.81). The least five existing facilities based on ranking of the mean item score are: Esplanade (0.70), beachfront (0.68), restaurant and bar (0.60), conveniences and parking (0.58).

\subsubsection{Conference Facilities}

Conference facilities were ranked as the most occurring factor by all the respondents; this factor is very important to most of the respondents because it enhances group meetings for most tourists that came in groups. It is also understandable because when tourists come in groups, they may arrange for meetings, conferences or seminars. Some establishments may intentionally take time off their respective duties during weekends to have quiet time in such tourist venues where they can brainstorm in the conference hall.

Much as this is an important factor in effective water tourism, the researchers disagree that conference facilities are the most occurring at the sites surveyed. This may require further research to confirm the results.

\subsubsection{Lodging}

This factor was ranked as the second most occurring by all respondents as can be seen in Table 3 . Any visitor to a tourist destination that wants to stay more than a day will need accommodation, hence the provision of this facility. Most of the respondents appreciated the fact that lodging is essential for effective tourism.

Lodging is also an important factor at tourist destinations. However, the researchers disagree that lodging facilities occur at the sites surveyed. This may also require further research to confirm the results.

\subsubsection{Water Sports and Swimming}

These facilities were ranked third and fourth in the overall analysis. The high ranking of these factor by the respondents is expected because most of them engage in water sports and swimming in most of the tourists destinations.

\subsubsection{Ferries, Piers and Marina}

These facilities came fifth in the overall analysis. They enhance the movement of tourists on water in the various tourist destinations, hence the importance attached to these facilities by the respondents.

Table 3. Importance attached to facilities at existing coastal destinations

\begin{tabular}{ccc}
\hline Available Facilities & M.I.S & Rank \\
\hline Conference Facilities & 0.91 & 1 \\
Lodging & 0.89 & 2 \\
Water Sports & 0.87 & 3 \\
Swimming & 0.85 & 4 \\
Ferries, Piers & 0.81 & 5 \\
Sightseeing Tours/Boating, Canoeing, Sailing Facilities & 0.80 & 6 \\
Facilities for constant Electricity Supply & 0.75 & 8 \\
Arts and Crafts & 0.74 & 9 \\
Shopping Facilities & 0.71 & 10 \\
Esplanade & 0.70 & 11 \\
Beachfront & 0.68 & 12 \\
Restaurant and Bar & 0.60 & 13 \\
Conveniences/Parking & 0.58 & 14 \\
\hline
\end{tabular}




\subsection{Coastal Tourism Factors}

The importance of 26 coastal tourism factors was assessed from the responses as shown in Table 4. From the table the ten most important factors (based on the ranking of the mean item scores are: Maintenance of existing facilities and Water pollution (0.85); Security (0.81); Safety Concerns (0.80); Water Quality (0.79); Site's Landscaping and Transportation (0.78); and Beautiful Scenery, and Designed Rest Areas, and Lighting and Signage (0.77). The ten least important courses are: Culture of Adjourning Communities/Adjourning Land uses (0.68); Accessibility to Site and Proximity to Hotels (0.66); Provision of Yachting, Boating facilities and Packaged Tours (0.65); Congestion of Site (0.64); Availability of Commercial facilities and Seating (0.63) (See Table 4 for other details).

Table 4. Importance of coastal tourism factors

\begin{tabular}{|c|c|c|}
\hline Coastal tourism factors & M.I.S & Rank \\
\hline Maintenance of existing Facilities & 0.85 & 1 \\
\hline Water pollution & 0.85 & 1 \\
\hline Security & 0.81 & 3 \\
\hline Safety Concerns & 0.80 & 4 \\
\hline Water Quality & 0.79 & 5 \\
\hline Site's Landscaping & 0.78 & 6 \\
\hline Transportation & 0.78 & 6 \\
\hline Beautiful Scenery & 0.77 & 8 \\
\hline Designed rest areas & 0.77 & 8 \\
\hline Lighting and Signage & 0.77 & 8 \\
\hline Natural Ecology & 0.76 & 11 \\
\hline Availability of Night life & 0.75 & 12 \\
\hline Adjourning Views & 0.73 & 13 \\
\hline Provision of Water Sports & 0.72 & 14 \\
\hline Shopping and auxiliary facilities & 0.70 & 15 \\
\hline Unsightly views & 0.70 & 15 \\
\hline Parking and Conveniences & 0.70 & 15 \\
\hline Culture of Adjourning communities and Adjourning Land uses & 0.68 & 18 \\
\hline Accessibility to Site & 0.66 & 19 \\
\hline Proximity to Hotels & 0.66 & 19 \\
\hline Provision of Yachting & 0.65 & 21 \\
\hline Boating Facilities & 0.65 & 21 \\
\hline Packaged Tours & 0.65 & 21 \\
\hline Congestion of site & 0.64 & 24 \\
\hline Availability of Commercial Facilities and Seating & 0.63 & 25 \\
\hline Provision of Infrastructures & 0.62 & 26 \\
\hline
\end{tabular}

\subsubsection{Maintenance of Existing Facilities and Water Pollution}

This factor was ranked as having the greatest impact in the promotion of coastal tourism. The researchers agree with the result in that when facilities are not maintained, the expectations of the tourists will not be met and in the long-run most of the regular visitors may stop patronizing such destinations. Water pollution is dangerous to health and this may also discourage tourist patronage to such destinations when there is clear evidence of water pollution at a tourist destination.

\subsubsection{Security and Safety Concerns}

These were ranked second and third by the respondents. This is understandable since an average tourist wants to secure his or her life and belongings

\subsubsection{Water Quality}

The result in Table 4 also indicates that water quality based on the responses of the respondents had great impact on the popularity of tourist destinations. This means that if the quality of water is good, it may increase the population of tourists at the destinations. 


\subsubsection{Site's Landscaping and Transportation}

These factors were also rated high as having impact on the popularity of selected tourist destinations. The authors are in agreement with result because a tourist site's landscaping that is beautiful may be an attraction to tourists who may be close nature. Transportation is equally important as this facilitates movement of the tourists in and out of their accommodation to the various tourist destinations.

\subsubsection{Beautiful Scenery, Designed Rest Areas, Lighting and Signage}

These factors were equally ranked high as affecting the popularity of coastal tourist destinations. This result is expected by the researchers because beautiful scenery, designed rest areas, lighting and signage within various tourist sites will attract more tourists because most visitors that had a memorable time at the sites will invite their friends next time they have opportunity to visit the tourist destination.

\subsection{Research Hypothesis}

The study postulates that the facilities provided and the identified coastal tourism factors do not have any significant impact on coastal tourist destinations in Lagos. Chi- square test was used to test the hypothetical statement. The result is shown in Table 5 and 6.

Results in Table 5 indicates that all the identified facilities are significant facilities that tourist appreciate so much in tourism destinations. Conference facilities, , Lodging, water sports, Swimming, ferries and piers, Sailing facilities, constant electricity supply, Arts and Crafts, Esplanade, Beachfront, Restaurant and Bar, Conveniences and Parking have their chi- square calculated values $\left(\chi^{2}\right.$ cal $=21.36,21.33,21.33,21.33,21.33,21.33,21.36$, $5.33,8.00,5.33,8.00,5.33)$ higher than their chi- square tabulated values $\left(\chi^{2}\right.$ tab $=3.84,3.84,3.84,3.84,3.84$, $3.84,3.84,3.84,3.84,5.99,3.84,5.99,3.84)$, it means alternative hypothesis (H1) is to be accepted for all the identified facilities at various coastal destination centers and this states that the facilities provided have significant impact on coastal tourist destinations in Lagos.

Table 5. Chi-square test result on facilities at coastal destinations

\begin{tabular}{ccccccc}
\hline Factors & $\chi^{2}$ cal & DF & $\chi^{2}$ tab & P- Value & Sig & Decision \\
\hline Conference facilities & 21.36 & 1 & 3.84 & 0.000 & $\mathrm{~S}$ & Accept $\mathrm{H}_{1}$ \\
Lodging & 21.33 & 1 & 3.84 & 0.000 & $\mathrm{~S}$ & Accept $\mathrm{H}_{1}$ \\
Water Sports & 21.33 & 1 & 3.84 & 0.000 & $\mathrm{~S}$ & Accept $\mathrm{H}_{1}$ \\
Swimming & 21.33 & 1 & 3.84 & 0.000 & $\mathrm{~S}$ & Accept $\mathrm{H}_{1}$ \\
Ferries and Piers & 21.33 & 1 & 3.84 & 0.000 & $\mathrm{~S}$ & Accept $\mathrm{H}_{1}$ \\
Sailing Facilities & 21.33 & 1 & 3.84 & 0.000 & $\mathrm{~S}$ & Accept $\mathrm{H}_{1}$ \\
Constant electricity supply & 21.36 & 1 & 3.84 & 0.000 & $\mathrm{~S}$ & Accept $\mathrm{H}_{1}$ \\
Arts and Crafts & 5.33 & 1 & 3.84 & 0.021 & $\mathrm{~S}$ & Accept $\mathrm{H}_{1}$ \\
Esplanade & 8.00 & 2 & 5.99 & 0.018 & $\mathrm{~S}$ & Accept $\mathrm{H}_{1}$ \\
Beachfront & 5.33 & 1 & 3.84 & 0.021 & $\mathrm{~S}$ & Accept $\mathrm{H}_{1}$ \\
Restaurant and Bar & 8.00 & 2 & 5.99 & 0.018 & $\mathrm{~S}$ & Accept $\mathrm{H}_{1}$ \\
Conveniences and Parking & 5.33 & 1 & 3.84 & 0.021 & $\mathrm{~S}$ & Accept $\mathrm{H}_{1}$ \\
\hline
\end{tabular}

Results in Table 6 indicates that all the coastal tourism factors are significant factors that tourist appreciate so much in tourism destinations. Maintenance of existing facilities, Water pollution, Security, Safety concerns, Water quality, Sites landscaping, transportation, beautiful scenery, designed rest areas, lighting and signage, natural ecology, availability of night life, adjourning views, provision of water sports, shopping and ancillary facilities, unsightly views, parking and conveniences, culture of adjourning communities and land use, accessibility to site, proximity to hotel, provision of yachting, boating facilities, packaged tours, congestion of site ,availability of commercial facilities and seating, provision of infrastructures have their chi- square calculated values $\left(\chi^{2} \mathrm{cal}=21.36,21.36,21.36,21.36,21.33,21.33,21.33,21.33,21.33,21.33,21.33,21.33\right.$, $21.33,21.33,21.33,21.33,21.33,21.33,21.33,5.33,5.33,5.33,5.33,5.33,5.33,5.33,5.33,5.33,8.00,8.00$, $8.00)$ higher than their chi- square tabulated values $\left(\chi^{2}\right.$ tab $=3.84,3.84,3.84,3.84,3.84,3.84,3.84,3.84,3.84$, $3.84,3.84,3.84,3.84,3.84,3.84,3.84,3.84,3.84,3.84,3.84,3.84,3.84,3.84,3.84,3.84,3.84,3.84,5.99,5.99$, 5.99), it means alternative hypothesis (H1) is to be accepted for all the factors at various coastal destination centers and this states that the coastal tourism factors provided have significant impact on coastal tourist destinations in Lagos. 
Table 6. Chi-square test result on coastal tourism factors

\begin{tabular}{|c|c|c|c|c|c|c|}
\hline Factors & $\chi^{2}$ cal & $\mathrm{DF}$ & $\chi^{2}$ tab & P- Value & Sig & Decision \\
\hline Maintenance of existing Facilities & 21.36 & 1 & 3.84 & 0 & $\mathrm{~S}$ & Accept $\mathrm{H}_{1}$ \\
\hline Water Pollution & 21.36 & 1 & 3.84 & 0 & $\mathrm{~S}$ & Accept $\mathrm{H}_{1}$ \\
\hline Security & 21.36 & 1 & 3.84 & 0 & $\mathrm{~S}$ & Accept $\mathrm{H}_{1}$ \\
\hline Safety concerns & 21.36 & 1 & 3.84 & 0 & $\mathrm{~S}$ & Accept $\mathrm{H}_{1}$ \\
\hline Water quality & 21.33 & 1 & 3.84 & 0 & $\mathrm{~S}$ & Accept $\mathrm{H}_{1}$ \\
\hline Sites Landscaping & 21.33 & 1 & 3.84 & 0 & $\mathrm{~S}$ & Accept $\mathrm{H}_{1}$ \\
\hline Transportation & 21.33 & 1 & 3.84 & 0 & $\mathrm{~S}$ & Accept $\mathrm{H}_{1}$ \\
\hline Beautiful Scenery & 21.33 & 1 & 3.84 & 0 & $\mathrm{~S}$ & Accept $\mathrm{H}_{1}$ \\
\hline Designed rest areas & 21.33 & 1 & 3.84 & 0 & $\mathrm{~S}$ & Accept $\mathrm{H}_{1}$ \\
\hline Lighting and Signage & 21.33 & 1 & 3.84 & 0 & $\mathrm{~S}$ & Accept $\mathrm{H}_{1}$ \\
\hline Natural Ecology & 21.33 & 1 & 3.84 & 0 & $\mathrm{~S}$ & Accept $\mathrm{H}_{1}$ \\
\hline Availability of night life & 21.33 & 1 & 3.84 & 0 & $\mathrm{~S}$ & Accept $\mathrm{H}_{1}$ \\
\hline Adjourning views & 21.33 & 1 & 3.84 & 0 & $\mathrm{~S}$ & Accept $\mathrm{H}_{1}$ \\
\hline Provision of water sports & 21.33 & 1 & 3.84 & 0 & $\mathrm{~S}$ & Accept $\mathrm{H}_{1}$ \\
\hline Shopping and ancillary facilities & 21.33 & 1 & 3.84 & 0 & $\mathrm{~S}$ & Accept $\mathrm{H}_{1}$ \\
\hline Unsightly views & 21.33 & 1 & 3.84 & 0 & $\mathrm{~S}$ & Accept $\mathrm{H}_{1}$ \\
\hline Parking and Conveniences & 21.33 & 1 & 3.84 & 0 & $\mathrm{~S}$ & Accept $\mathrm{H}_{1}$ \\
\hline Culture of adjourning communities/land use & 5.33 & 1 & 3.84 & 0.021 & $\mathrm{~S}$ & Accept $\mathrm{H}_{1}$ \\
\hline ccessibility to site & 5.33 & 1 & 3.84 & 0.021 & $\mathrm{~S}$ & Accept $\mathrm{H}_{1}$ \\
\hline Proximity to Hotels & 5.33 & 1 & 3.84 & 0.021 & $\mathrm{~S}$ & Accept $\mathrm{H}_{1}$ \\
\hline Provision of yachting & 5.33 & 1 & 3.84 & 0.021 & $\mathrm{~S}$ & Accept $\mathrm{H}_{1}$ \\
\hline Boating facilities & 5.33 & 1 & 3.84 & 0.021 & $\mathrm{~S}$ & Accept $\mathrm{H}_{1}$ \\
\hline Packaged Tours & 5.33 & 1 & 3.84 & 0.021 & $\mathrm{~S}$ & Accept $\mathrm{H}_{1}$ \\
\hline Congestion of Site & 5.33 & 1 & 3.84 & 0.021 & $\mathrm{~S}$ & Accept $\mathrm{H}_{1}$ \\
\hline Availability of commercial facilities and & 8 & 2 & 5.99 & 0.018 & $\mathrm{~S}$ & Accept $\mathrm{H}_{1}$ \\
\hline Seating & 8 & 2 & 5.99 & 0.018 & $\mathrm{~S}$ & Accept $\mathrm{H}_{1}$ \\
\hline Provision of Infrastructures & 8 & 2 & 5.99 & 0.018 & $\mathrm{~S}$ & Accept $\mathrm{H}_{1}$ \\
\hline
\end{tabular}

\section{Conclusions and Recommendations}

The findings from the three basic objectives that the study examined indicates that the patronage of various tourist destination centers in Lagos is still at a very low turnout, that is earnings through tourism in destinations investigated is still very low. The study also highlighted the facilities that are available in these tourist destinations. The study revealed that most of the tourist destinations have conference facilities, lodging, water sports, swimming facilities and ferries but not all have conveniences, parking, restaurant and bar, beachfront and esplanade. The test of hypothesis confirmed that all the identified facilities and costal tourism factors are significant. There is need for the tourism management board and government officials in charge of formulating policies for tourism in Nigeria to mandate all tourism destinations to provide the following in their respective tourism destinations: conveniences and parking, restaurant and bar, beachfront and esplanade. Equally important is the formulation of policies that will endure that all physical facilities within various coastal destinations are maintained regularly, regular inspection of these facilities should be carried out by the tourist board. Adequate security and safety must be ensured at tourist destinations. The management of various tourist destinations must ensure that there is adequate means of transportation for the tourist. Good water quality and site's landscaping is also recommended.

\section{References}

Adejumo, O. T. (2010). Eleko rural beach initiative: Maximizing economic benefit of domestic tourism destination in littoral Lagos community. Urban and Regional Planning Review, 2(1\&2), 91-98.

Aziz, A., \& Zainol, N. A. (2009). Local and foreign tourists' image of highland tourism destinations in Peninsular Malaysia. Pertanika Journal of Social Science \& Humanities, 17(1), 33-46.

Blank, U. (1989). The community tourism industry imperative. Venture Publishing Inc., State College, PA.

Burton, R. (1995). Travel Geography. Harlow, UK: Longman. 
Formica, S. (2000). Tourism attractiveness as a function of supply and demand interaction. Unpublished doctoral dissertation, Virginia: Virginia Polytechnic Institute and State University, Blacksburg, Virginia.

Gunn, C. A. (1994). Tourism Planning (3rd Ed). New York: Taylor and Francis.

Inskeep, E. (1994). National and Regional Tourism Planning. New York, NY: Routledge.

Küce, S. (2001). Tourism Trends \& Tourism Policies in Turkey. Seminar On Tourism Policy and Economic Growth, Session II: The Tourism Industry in selected economies: assessment, experience, comparisons. Berlin, Organization for Economic Cooperation and Development.

Lickorish, L. J., \& Jenkins, C. L. (1997). An introduction to tourism. London: Butterworth Heinemann,

McIntosh, R. W., Goeldner, C. R., \& Ritchie, J. R. (1995). Tourism Principles, Practices, Philosophies. New York: John Wiley \& Sons.

Oldham, G., Creemers, G., \& Rebeck, T. (2000). An economic evaluation of tourism: A case study of accommodation facilities in southern Maputaland. Development Southern Africa, 17(2), 175-188. http://dx.doi.org/10.1080/713661403

Rutin, J. (2010). Coastal tourism: A comparative study between Croatia and Tunisia. Tourism Geographies, 12(2), 264-277. http://dx.doi.org/10.1080/14616681003725227 